\title{
CUIDADO HUMANIZADO DO ENFERMEIRO AO PACIENTE ONCOLÓGICO FORA DE POSSIBILIDADE DE CURA
}

\author{
HUMANIZED CARE FROM NURSE TO PATIENT OUT OF POSSIBILITY OF \\ CANCER CURE
}

\author{
Silvanéia Santana Xavier', karla Ferraz dos Anjos' ${ }^{2}$, Kelly Cruz Pimentel Sampaio', Akemy \\ Brandão Mochizuki', Vanessa Cruz Santos² \\ Faculdade Maurício de Nassau ${ }^{1}$, Universidade Federal da Bahia - UFBA ${ }^{2}$
}

\begin{abstract}
Several people have been affected by cancer, with diagnosis of patients outside the possibility of healing and with demand for palliative care. Study aims to analyze the scientific production about humanized care from nurse to patient out of possibility to cure cancer. Systematic review developed from the SCIELO database in which there was made crossings of descriptors and selected seven articles to compose the sample, published in the period from 2003 through February 2017. The results showed the need for training nurses on humanized care to the patient out of possibility of curing cancer. This demand has influence on graduation due to lack of opportunities and experience of nursing students with these patients and deficit of content in the curriculum from the perspective of the terminally ill. Communication is the strategy that strengthens the bond and trust between the nurse, the patient and the family, and promotes the humanization of palliative care. It is concluded that humanized care from nurse to patient out of cancer possibility of healing has occurred so early, even recognizing this as fundamental to minimize the anguish, pain and suffering of those involved: professional, patient and family.
\end{abstract}

Key words: nursing care, palliative care, terminally ill, humanization in assistance.

\section{Resumo}

Várias pessoas têm sido acometidas por câncer com diagnóstico de pacientes fora de possibilidade de cura e com demanda de cuidados paliativos. Estudo objetiva analisar a produção científica sobre cuidado humanizado do enfermeiro ao paciente oncológico fora de possibilidade de cura. Revisão sistemática desenvolvida a partir da base de dados SCIELO, na qual foram feitos cruzamentos dos descritores $e$ selecionado sete artigos para compor a amostra, publicados no período de 2003 a fevereiro 2017. Os resultados evidenciaram a necessidade de capacitação dos enfermeiros para o cuidado humanizado ao paciente oncológico fora de possibilidade de cura. Essa demanda tem influência na graduação devido à carência de oportunidades e vivência dos estudantes de enfermagem com esses pacientes e déficit de conteúdos no currículo na perspectiva da terminalidade. A comunicação é estratégia que fortalece $o$ vínculo e a confiança entre $o$ enfermeiro, o paciente e a família, e favorece a humanização dos cuidados paliativos. Conclui-se que o cuidado humanizado do enfermeiro ao paciente oncológico fora de possibilidade de cura tem ocorrido de forma incipiente, mesmo reconhecendo este como fundamental para minimizar a angustia, a dor e o sofrimento dos envolvidos: profissional, paciente e família.

Palavras chave: cuidados de enfermagem, cuidados paliativos, doente terminal, humanização na assistência. 


\section{Introdução}

É considerado paciente fora de possibilidade de cura ou paciente terminal quando "se esgotam as possibilidades de resgate das condições de saúde do paciente e a possibilidade de morte próxima parece inevitável e previsível. O paciente se torna "irrecuperável" e caminha para a morte sem que se consiga reverter este caminhar ${ }^{1: 92}$. Esses pacientes mesmo com prognóstico ruim, precisam de cuidado humanizado. Neste contexto, o cuidado paliativo é necessário para a continuidade de uma vida dignidade e com menos sofrimento.

A Organização Mundial de Saúde (OMS) define cuidados paliativos como uma assistência ofertada por equipe multidisciplinar, cujo propósito é a melhoria da qualidade de vida (QV) do paciente e de seus familiares, diante de uma doença grave como o câncer, por meio da prevenção e alívio do sofrimento e controle da dor, assim como de outros sintomas apresentados pelo paciente ${ }^{2}$.

Entre as doenças que acometem as pessoas que demandam de cuidados paliativos, pode-se citar o câncer, este é considerado um conjunto de mais de 100 doenças, na qual ocorre crescimento desordenado do quantitativo de células invasoras do organismo. Estas, por sua vez, se dividem e reproduzem de forma desordenada, formando tumores malignos, que podem ser bastante agressivos ${ }^{3}$.

Nota-se que, em media " 8,2 milhões de pessoas morrem por ano de câncer no mundo, e no Brasil foram registradas 189.454 mortes por câncer. Para o ano de 2016, estimou-se a ocorrência de mais de 596 mil casos da doença no país" ${ }^{\text {4:1 }}$. O quantitativo de pessoas acometidas por câncer é elevado e, a depender da evolução da doença e suas complicações, os cuidados paliativo é de fundamental relevância, sobretudo quando a pessoa é diagnosticada fora de possibilidade de cura.

No Brasil, os cuidados paliativos têm se ampliado diante o reconhecimento de sua importância para pacientes fora de possibilidade de cura, uma vez que pode favorecer o bemestar. Nestes pacientes, a dor e o sofrimento são vistos como inerente ao quadro clínico, o que impossibilita, muitas vezes, a participação ativa destes na tomada de decisão sobre seus cuidados no fim da vida. Assim sendo, mesmo que diversas vezes é negligenciada, é necessário apoiar a família dos pacientes em finitude devido a iminência da perda, do sofrimento e do luto ${ }^{5}$. Os profissionais de saúde, como enfermeiros, precisam respeitar a autonomia das pessoas em cuidados paliativos, visto, a complexidade da situação.

Entre os pacientes, quando se esgotam a possibilidade de cura, a atenção a saúde precisa ser direcionada na busca da QV. Esta, por sua vez, pode ser favorecida por meio do conforto, alívio da dor, controle dos sintomas estressantes e; apoio espiritual, psicossocial e no enlutamento ${ }^{6}$. Essas intervenções desenvolvidas pelos profissionais de saúde favorecem o cuidado responsável e humanizado.

A humanização, na área da saúde, tem relação com a "valorização dos diferentes sujeitos implicados no processo de produção de saúde: usuários, trabalhadores e gestores" ${ }^{\prime 7: 8}$. Diante a relevância da humanização dos cuidados em saúde, o Ministério da Saúde (MS) cria a Política Nacional de Humanização (PNH), do Sistema Único de Saúde (SUS).

Entre as orientações da PNH estão "o fortalecimento de trabalho em equipe multiprofissional, fomentando a transversalidade e, a construção de autonomia e protagonismo dos sujeitos e coletivos implicados na rede do SUS $^{\prime \prime 7: 21}$. Estes são importantes para os profissionais, dentre eles enfermeiros, que cuidam de pacientes fora de possibilidade de cura. Isto porque o cuidado paliativo demanda conhecimentos de várias áreas e de forma interdisciplinar.

Os cuidados paliativos se configuram em uma abordagem mais humana principalmente diante da dor vivenciada na terminalidade ${ }^{8}$. Como membro da equipe de saúde, os enfermeiros precisam em seu cotidiano de trabalho ofertar um cuidado humanizado aos pacientes fora de possibilidade de cura.

O enfermeiro que cuida de paciente oncológico que não tem mais possibilidades de cura precisa se atentar no tempo de vida que ele tem ${ }^{9}$. Este profissional ao prestar os cuidados paliativos a pessoa acometida por câncer, necessita orientar de maneira clara e objetiva o paciente e sua família nos cuidados a serem prestados, com o propósito de favorecer o bemestar dos envolvidos ${ }^{10}$. "Os cuidados de enfermagem envolvem o fornecimento de conforto, manutenção da vida, atendimento das necessidades físicas e emocionais" ${ }^{11: 6}$.

Diante o contexto, nota-se que apesar da relevância dos cuidados humanizado do enfermeiro ao paciente com câncer fora de possibilidade de cura, este tem ocorrido de 
maneira incipiente em várias instituições de saúde, logo estudo se torna relevante uma vez que poderá contribuir para produção do conhecimento no campo da saúde.

Estudo tem por objetivo analisar o cuidado humanizado do enfermeiro ao paciente oncológico fora de possibilidade de cura.

\section{Metodologia}

Estudo de revisão sistemática da literatura, realizado a partir da busca dos artigos feita no período de 2003 a fevereiro 2017. A seleção do ano ocorreu devido a Política Nacional de Humanização ter sido criada em 2003 e sua escolha justifica-se em seus princípios ${ }^{7}$. Esta foi considerada por acreditar que os enfermeiros ao trabalharem com cuidados paliativos fundamentam sua prática na humanização do cuidado.

Para este estudo utilizou-se a questão de pesquisa: o que tem produzido sobre cuidado humanizado do enfermeiro ao paciente oncológico fora de possibilidade de cura? Para a busca dos artigos optou-se pela base de dados Scientific Electronic Library Online (SciELO), na qual utilizou-se os descritores: oncologia, cuidados paliativos, doente terminal, humanização na assistência e cuidados de enfermagem. Realizou-se os cruzamentos dos descritores a partir do operador booleano "AND". A coleta dos dados ocorreu no período de fevereiro a março de 2017.

Utilizou-se como critério de inclusão: artigos completos, em português e originais, que abordavam sobre o cuidado do enfermeiro, a importância dos cuidados paliativos, a humanização da assistência, paciente com câncer e terem sido realizados em ambiente hospitalar. E, como critérios de exclusão: artigos de revisões e de validação de conteúdo, estudo de caso; tese, artigos duplicados, assim como os artigos que abordavam a equipe multiprofissional e os de enfermagem (auxiliares e técnicos) juntos.

Inicialmente foi feita a busca individual dos artigos na base de dados na qual encontrou 2.278 manuscritos. Posteriormente realizou-se o cruzamento dos descritores: cuidados paliativos AND cuidados de enfermagem; cuidados paliativos AND doente terminal; cuidados paliativos AND oncologia; cuidados paliativos AND humanização da assistência, totalizando 51 artigos. Em seguida, realizou-se leitura dos títulos, restando-se 24 artigos. Por fim, foi feita a leitura dos resumos e métodos, restando o total de 12 artigos e, após sua leitura na íntegra, restaram sete para análise, conforme Quadro 1. Os dados foram analisados e apresentados de forma descritiva.

Quadro 1- Descrição da busca dos artigos na base de dados SciELO. Salvador, Bahia, Brasil, 2017.

\begin{tabular}{|c|c|c|c|c|c|}
\hline \multicolumn{5}{|c|}{ Busca eletrônica de artigos na base de dados } & \multirow{2}{*}{$\begin{array}{l}\text { Total } \\
2.278\end{array}$} \\
\hline $\begin{array}{c}\text { Cuidados } \\
\text { paliativos } \\
191 \\
\end{array}$ & $\begin{array}{c}\text { Doente terminal } \\
31\end{array}$ & $\begin{array}{c}\text { Oncologia } \\
838\end{array}$ & $\begin{array}{l}\text { Cuidados de } \\
\text { Enfermagem } \\
989 \\
\end{array}$ & $\begin{array}{l}\text { Humanização na } \\
\text { Assistência } \\
229\end{array}$ & \\
\hline \multicolumn{6}{|c|}{ Interlocuções dos descritores } \\
\hline $\begin{array}{c}\text { Cuidados } \\
\text { paliativos AND } \\
\text { doente terminal } \\
10\end{array}$ & $\begin{array}{c}\text { Cuidado paliativo } \\
\text { AND oncologia } \\
27\end{array}$ & $\begin{array}{l}\text { Cuidado paliativo } \\
\text { AND cuidados de } \\
\text { Enfermagem } \\
10\end{array}$ & \multicolumn{2}{|c|}{$\begin{array}{c}\text { Cuidados paliativos AND } \\
\text { Humanização na Assistência } \\
4\end{array}$} & $\underline{51}$ \\
\hline \multicolumn{6}{|c|}{ Seleção após leitura de títulos } \\
\hline $\begin{array}{c}\text { Cuidado } \\
\text { paliativo AND } \\
\text { doente terminal } \\
5\end{array}$ & $\begin{array}{c}\text { Cuidado paliativo } \\
\text { AND oncologia } \\
11\end{array}$ & $\begin{array}{l}\text { Cuidado paliativo } \\
\text { AND cuidados de } \\
\text { Enfermagem } \\
5\end{array}$ & $\begin{array}{r}\text { Cuidados } \\
\text { Humanizaç }\end{array}$ & $\begin{array}{l}\text { aliativos AND } \\
\text { o na Assistência } \\
3\end{array}$ & $\underline{24}$ \\
\hline \multicolumn{6}{|c|}{ Após critério de inclusão a partir da leitura de resumo e método } \\
\hline $\begin{array}{c}\text { Cuidado } \\
\text { paliativo AND } \\
\text { doente terminal } \\
2\end{array}$ & $\begin{array}{c}\text { Cuidado paliativo } \\
\text { AND oncologia } \\
7\end{array}$ & $\begin{array}{l}\text { Cuidados } \\
\text { Paliativos AND } \\
\text { Cuidados de } \\
\text { Enfermagem } \\
2\end{array}$ & $\begin{array}{r}\text { Cuidados } \\
\text { Humanizaç }\end{array}$ & $\begin{array}{l}\text { aliativos AND } \\
\text { o na Assistência } \\
1\end{array}$ & $\underline{12}$ \\
\hline \multicolumn{5}{|c|}{ Seleção dos artigos para análise após leitura na íntegra } & 7 \\
\hline
\end{tabular}




\section{Resultados e Discussões}

Os sete artigos incluídos na amostra foram analisados na íntegra. A exploração do conteúdo ocorreu de forma detalhada em todas as sessões do texto. O Quadro 2 apresenta as características dos artigos analisados, no qual descreve número, autores, periódicos, ano de publicação, tipo de estudo e método (participante e local). O Quadro 3 descreve os títulos, objetivos e principais resultados e conclusões dos estudos analisados.

Quadro 2- Caracterização dos artigos selecionados na busca de dados para análise. Salvador, Bahia, 2017

\begin{tabular}{|c|c|c|c|c|c|}
\hline № & Autor & Periódico & Ano & Tipo de estudo & Participantes/ local \\
\hline 1 & Silva MS, Moreira MC ${ }^{12}$ & Acta Paul Enferm & 2011 & $\begin{array}{l}\text { Descritivo } \\
\text { qualitativo. }\end{array}$ & $\begin{array}{l}\text { Oito enfermeiras. } \\
\text { Hospital do câncer. } \\
\text { Rio de janeiro Brasil. }\end{array}$ \\
\hline 2 & $\begin{array}{l}\text { Peterson AA, Carvalho } \\
\mathrm{EC}^{13}\end{array}$ & $\begin{array}{l}\text { Rev. Brasileira de } \\
\text { Enfermagem, } \\
\text { Brasília. }\end{array}$ & 2011 & Descritivo. & $\begin{array}{l}56 \text { enfermeiros. } \\
\text { Hospital Universitário. } \\
\text { São Paulo. }\end{array}$ \\
\hline 3 & \begin{tabular}{|lr} 
Monteiro & ACM, \\
Rodrigues & BMRD, \\
Pacheco STA $^{14}$ &
\end{tabular} & Esc. Anna Nery & 2012 & Descritivo. & $\begin{array}{l}12 \text { Enfermeiros. } \\
\text { Hospital especializado } \\
\text { em oncologia. } \\
\text { Rio de Janeiro. }\end{array}$ \\
\hline 4 & $\begin{array}{l}\text { França JRFS, Costa SFG, } \\
\text { Lopes MEL, Nóbrega } \\
\text { MML, França ISX } X^{15}\end{array}$ & $\begin{array}{l}\text { Rev. Latino-Am } \\
\text { Enfermagem }\end{array}$ & 2013 & Qualitativo. & $\begin{array}{l}10 \text { enfermeiros. } \\
\text { Hospital público } \\
\text { brasileiro. } \\
\text { João Pessoa. }\end{array}$ \\
\hline 5 & $\begin{array}{l}\text { Souza LF, Misko MD, Silva } \\
\text { L, Poles k, Santos MR, } \\
\text { Bousso RS }{ }^{16}\end{array}$ & $\begin{array}{l}\text { Rev. Escola de } \\
\text { enfermagem USP }\end{array}$ & 2013 & $\begin{array}{l}\text { Exploratório } \\
\text { descritivo. }\end{array}$ & $\begin{array}{l}\text { Oito enfermeiros. } \\
\text { Hospital público. } \\
\text { São Paulo. }\end{array}$ \\
\hline 6 & 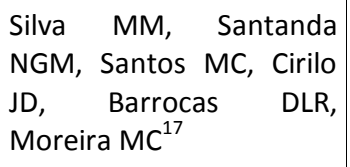 & $\begin{array}{ll}\text { Revista de } & \text { dermagem da } \\
\text { Escola Anna Nery }\end{array}$ & 2015 & Descritivo. & $\begin{array}{l}13 \text { enfermeiras. } \\
\text { Hospital universitário } \\
\text { Rio de Janeiro. }\end{array}$ \\
\hline 7 & $\begin{array}{l}\text { Silveira NR, Nascimento } \\
\text { ERP, Rosa LM, Jung W, } \\
\text { Martins SR, Fontes MS }{ }^{18}\end{array}$ & $\begin{array}{l}\text { Rev. Brasileira de } \\
\text { Enferm }\end{array}$ & 2016 & $\begin{array}{l}\text { Exploratório } \\
\text { descritivo. }\end{array}$ & $\begin{array}{l}\text { 30enfermeiros } \\
\text { Hospital } \\
\text { Florianópolis }\end{array}$ \\
\hline
\end{tabular}


Quadro 3- Descrição dos títulos, objetivos e principais resultados e conclusões dos artigos analisados. Salvador, Bahia, 2017.

\begin{tabular}{|c|c|c|c|}
\hline $\begin{array}{c}\mathbf{N} \\
\underline{\mathbf{o}}\end{array}$ & Título & Objetivo do estudo & Principais resultados e conclusões \\
\hline 1 & $\begin{array}{l}\text { Sistematização da } \\
\text { assistência de } \\
\text { enfermagem em } \\
\text { cuidados paliativos } \\
\text { na oncologia: } \\
\text { visão dos } \\
\text { enfermeiros }^{12} \text { d }\end{array}$ & $\begin{array}{l}\text { Descrever a visão dos } \\
\text { enfermeiros a respeito } \\
\text { da sistematização (SAE) } \\
\text { e clientes com câncer } \\
\text { avançados em cuidados } \\
\text { paliativos. } \\
\text { Analisar os fatores } \\
\text { intervenientes na } \\
\text { implantação do SAE na } \\
\text { visão do enfermeiro, } \\
\text { Discutir possíveis } \\
\text { estratégias propostas } \\
\text { pelos enfermeiros que } \\
\text { favoreçam nama } \\
\text { implantação nesse } \\
\text { cenário. }\end{array}$ & $\begin{array}{l}\text { Indicou que a unidade hospitalar se encontrava na fase de } \\
\text { planejamento e implantação do SAE. } \\
\text { Evidenciou-se a necessidade de capacitação da equipe em } \\
\text { relação à fundamentação teórica e preparo para tomada de } \\
\text { decisão frente à complexidade da área de oncologia. } \\
\text { Dificuldade de sistematizar o cuidado ao paciente fora de } \\
\text { possibilidade de cura, marcado pelo cuidado cotidiano, com } \\
\text { as fragilidades humanas no limiar entre a vida e a morte. } \\
\text { Paciente em cuidado paliativo demanda do enfermeiro } \\
\text { constantes reavaliações de cada situação, exigindo ação e } \\
\text { decisão diante da urgência e da incerteza, assim como } \\
\text { requerem prática humanizada pautada em referenciais } \\
\text { dinâmicos e flexíveis. }\end{array}$ \\
\hline 2 & $\begin{array}{l}\text { Comunicação } \\
\text { terapêutica na } \\
\text { Enfermagem: } \\
\text { dificuldades para o } \\
\text { cuidar de idosos } \\
\text { com câncer }^{13}\end{array}$ & $\begin{array}{l}\text { Avaliar as dificuldades e } \\
\text { suas respectivas causas } \\
\text { na percepção do } \\
\text { enfermeiro, ao se } \\
\text { prestar assistência ao } \\
\text { paciente idoso, com } \\
\text { patologia oncológica. }\end{array}$ & $\begin{array}{l}\text { Carência de oportunidades e vivência do estudante durante } \\
\text { a formação profissional, de habilidades para lidar com } \\
\text { pacientes terminais. } \\
\text { Dificuldades dos enfermeiros de lidar com sentimentos } \\
\text { negativos relacionados ao câncer, interferindo no cuidado } \\
\text { de enfermagem. } \\
\text { Demanda procurar aprender e trabalhar habilidade que } \\
\text { visem não apenas na assistência técnica e pratica, mas a } \\
\text { assistência integral aos pacientes. } \\
\text { A assistência ao paciente oncológico, em estado terminal, } \\
\text { apresentou, em maior frequência, incidentes críticos } \\
\text { negativos, em especial os sentimentos de impotência e } \\
\text { tristeza. } \\
\text { Há descrições de intervenções de caráter técnico e prático } \\
\text { como de caráter humano como estabelecer vínculo, } \\
\text { procurar fazer o melhor ao paciente, oferecer apoio, ouvir o } \\
\text { paciente, dedicar-se até o final, transmitir sentimentos } \\
\text { positivos. } \\
\text { Reconhece a importância das ações de enfermagem } \\
\text { oferecerem assistência humana. } \\
\text { Há necessidade de capacitação dos enfermeiros para a } \\
\text { assistência paliativa, incentivando-os no desenvolvimento } \\
\text { de habilidades, que auxiliem o paciente a ter uma qualidade } \\
\text { de vida digna até o momento de sua morte, viabilizando a } \\
\text { humanização do cuidado. }\end{array}$ \\
\hline
\end{tabular}




\begin{tabular}{|c|c|c|c|}
\hline 3 & $\begin{array}{l}\text { O Enfermeiro e o } \\
\text { cuidar da criança } \\
\text { com câncer sem } \\
\text { possibilidade de } \\
\text { cura atual }^{14}\end{array}$ & $\begin{array}{l}\text { Analisar } \\
\text { compreensivamente o } \\
\text { cuidado do enfermeiro } \\
\text { à criança hospitalizada } \\
\text { portadora de doença } \\
\text { oncológica fora de } \\
\text { possibilidade de cura } \\
\text { atual. }\end{array}$ & $\begin{array}{l}\text { Na análise compreensiva surge duas categorias: conforto e } \\
\text { minimização da dor. } \\
\text { Os enfermeiros ao realizarem o cuidado à criança com } \\
\text { câncer e fora de possibilidade de cura enfatizaram a } \\
\text { necessidade de confortar a criança diante do seu estado de } \\
\text { adoecimento. } \\
\text { A atuação dos enfermeiros em cuidados paliativos deve } \\
\text { desempenhá-los a partir de uma visão humanística. } \\
\text { Expressaram a importância de promover ações para } \\
\text { minimizar a dor, avaliando e proporcionando o bem-estar } \\
\text { para esta clientela, tentando sempre minimizar o } \\
\text { sofrimento, realizando um cuidado individualizado e } \\
\text { direcionado para cada criança. } \\
\text { A preocupação em minimizar a dor no paciente com doença } \\
\text { oncológica, constitui em conduta humana. } \\
\text { Cuidado para a família dos pacientes, com intuito de apoiá- } \\
\text { la, proporcionando atitudes de carinho, afeto e respeito. }\end{array}$ \\
\hline 4 & $\begin{array}{l}\text { Importância da } \\
\text { comunicação nos } \\
\text { cuidados paliativos } \\
\text { em oncologia } \\
\text { pediátrica: } \\
\text { enfoque na Teoria } \\
\text { Humanística de } \\
\text { Enfermagem }^{15}\end{array}$ & $\begin{array}{lr}\text { Investigar e analisar a } \\
\text { comunicação nos } \\
\text { cuidados paliativos em } \\
\text { oncologia pediátrica: } \\
\text { enfoque na Teoria } \\
\text { Humanística } \\
\text { Enfermagem. }\end{array}$ & $\begin{array}{l}\text { Estratégias para humanizar o cuidado em enfermagem, com } \\
\text { ênfase no alivio do sofrimento da criança. } \\
\text { Estratégia para fortalecer o vínculo de confiança entre } \\
\text { enfermeiro e criança. } \\
\text { A comunicação se configura como um elemento eficaz no } \\
\text { cuidado com a criança com câncer. } \\
\text { A comunicação é de suma importância para a promoção dos } \\
\text { cuidados paliativos quando alicerçado na Teoria } \\
\text { Humanística de Enfermagem. } \\
\text { A Teoria humanista envolve um diálogo vivo, que envolve o } \\
\text { encontro entre, alguém para atender e alguém para ser } \\
\text { atendido, um processo comunicacional entre o ser que } \\
\text { cuida e o ser que é cuidado. } \\
\text { A comunicação e o alívio do sofrimento é relacionado a } \\
\text { estratégia para humanizar o cuidar de enfermagem. }\end{array}$ \\
\hline
\end{tabular}

Continua... 
...continuação

\begin{tabular}{|c|c|c|c|}
\hline 5 & $\begin{array}{l}\text { Morte digna da } \\
\text { criança: percepção } \\
\text { de enfermeiros de } \\
\text { uma unidade de } \\
\text { oncologia }^{16}\end{array}$ & $\begin{array}{l}\text { Identificar o significado } \\
\text { e as intervenções de } \\
\text { enfermeiros que atuem } \\
\text { em oncologia pediátrica } \\
\text { na promoção de morte } \\
\text { digna da criança }\end{array}$ & $\begin{array}{l}\text { Há conflito pessoal do profissional sobre resistir ou aceitar a } \\
\text { morte de uma criança como algo natural. } \\
\text { Reconhece a necessidade de educação sobre o tema } \\
\text { terminalidade. } \\
\text { A falta de respaldo legal e autonomia da enfermeira impede } \\
\text { a promoção da morte digna para a criança. } \\
\text { O enfermeiro que trabalha em oncologia pediátrica sente-se } \\
\text { privado de liberdade para tomar decisões ou agir com } \\
\text { autonomia nas situações que envolvem a morte da criança. } \\
\text { Existe preocupação evidente com as questões legais e } \\
\text { bioéticas envolvidas nas discussões sobre situações de final } \\
\text { de vida. } \\
\text { O enfermeiro cria vínculos com a criança e com a família. } \\
\text { Para oferecer o conforto físico para a criança, o enfermeiro } \\
\text { busca estratégias farmacológicas ou não farmacológicas que } \\
\text { cessem ou, pelo menos, aliviem a dor física da criança para } \\
\text { que seu sofrimento seja o menor possível. } \\
\text { No cuidado humanizado é abordado o ser como um todo, em } \\
\text { seus variados aspectos e singularidades. } \\
\text { A humanização do cuidado tem relação com o estar } \\
\text { presente, demonstrar carinho, ter respeito, ter presteza em } \\
\text { estar ao lado do paciente quando for de sua vontade, } \\
\text { oferecer-lhe palavra de conforto ou um colo para chorar. } \\
\text { Valorizar o cuidado humanizado tem relação com o respeito } \\
\text { à autonomia da família na execução de procedimentos e } \\
\text { condutas, em seus desejos e posições sobre a vida e a morte } \\
\text { do ente querido, logo, as condutas não se baseiam } \\
\text { unicamente nas opiniões da equipe ou desejo da equipe. }\end{array}$ \\
\hline 6 & $\begin{array}{l}\text { Cuidados } \\
\text { paliativos na } \\
\text { assistência de alta } \\
\text { complexidade em } \\
\begin{array}{l}\text { oncologia: } \\
\text { percepção de } \\
\text { enfermeiros }^{17}\end{array}\end{array}$ & 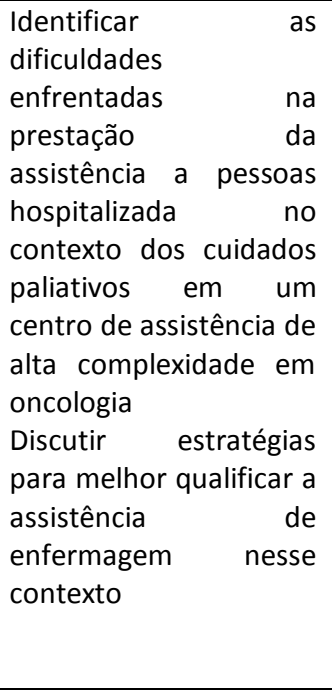 & $\begin{array}{l}\text { Há déficit de preparo do profissional enfermeiro para lidar } \\
\text { com situações que refletem a complexidade do ser humano } \\
\text { e o processo de morrer. } \\
\text { Enfermeiros encontram-se dificuldades em assistir as } \\
\text { pessoas em cuidados paliativos como as relacionadas com a } \\
\text { formação profissional, diante da falta de preparo para lidar } \\
\text { com situações que refletem a complexidade do ser humano } \\
\text { e o processo de morrer. } \\
\text { A carência de recursos materiais e de recursos humanos } \\
\text { como de equipe multiprofissional, assim como a ausência de } \\
\text { estrutura física adequada, dificultam o desenvolvimento de } \\
\text { cuidado de qualidade, individualizado e humanizado. } \\
\text { As enfermeiras encontram-se dificuldades em assistir as } \\
\text { pessoas em cuidados paliativos devido ausência de leitos } \\
\text { diferenciados para esse perfil de clientela, a influência do } \\
\text { modelo curativista, a carência da equipe multidisciplinar } \\
\text { voltada para atendimento das necessidades no final da vida; } \\
\text { e o cuidado desumanizado. }\end{array}$ \\
\hline 7 & $\begin{array}{l}\text { Cuidado paliativo } \\
\text { e enfermeiros da } \\
\text { terapia intensiva: } \\
\text { sentimentos que } \\
\text { ficam }^{18}\end{array}$ & $\begin{array}{l}\text { Conhecer os } \\
\text { sentimentos dos } \\
\text { enfermeiros acerca dos } \\
\text { cuidados paliativos em } \\
\text { unidades de terapia } \\
\text { intensiva de adultos }\end{array}$ & $\begin{array}{l}\text { Ideias centrais estão relacionadas aos sentimentos de } \\
\text { conforto, frustração, angustia e insegurança; } \\
\text { Há falta de comunicação e informação entre a equipe } \\
\text { multiprofissional. A falta de informação deixa a enfermeira } \\
\text { angustiada devido à demanda do cuidado paliativo. } \\
\text { A formação e atuação do enfermeiro ainda está voltado para } \\
\text { o curativo e isso causa angustia na profissional. } \\
\text { Enfermeira presta cuidado como se fosse ao paciente que } \\
\text { não está em cuidados paliativos. } \\
\text { Sente-se mais responsável ainda pelo paciente, porque não é } \\
\text { possível saber o tempo que ele vai permanecer nesse } \\
\text { modelo de cuidado. } \\
\text { Reconhece a necessidade em oferecer o cuidado de conforto } \\
\text { físico para redução da dor/sofrimento. }\end{array}$ \\
\hline
\end{tabular}


Entre os profissionais de saúde há relutância em diagnosticar o paciente fora de possibilidade de cura, isto porque este pode não se confirmar com a evolução do quadro clínico do paciente. Após diagnóstico definitivo, o profissional entra, muitas vezes, em conflito, e a eventual melhora do paciente, pode indicar erro no prognóstico, o que torna situação de angustia para alguns profissionais. Para tanto, a tomada decisão de não mais investir no paciente, no sentido de intervenções visando cura, é tomada por uma equipe de saúde e não por um profissional: incluindo também o posicionamento da família ${ }^{8}$.

Não é fácil para a equipe de saúde lhe dar com o paciente fora da possibilidade de cura. Alguns profissionais têm dificuldades, por exemplo, de comunicar o paciente o diagnóstico definitivo, informando somente o que consideram apropriado. Essa atitude influencia diretamente na autonomia das pessoas, uma vez que todos têm o direito de saber sobre sua condição de saúde ${ }^{19}$.

Não se pode dizer que o paciente que não mais há possibilidades de cura, não há mais o que fazer. É preciso ofertar a ele e sua família autonomia e respeitar suas escolhas e desejos. Os enfermeiros reconhecem a relevância da humanização nos cuidados paliativos e acreditam que a pessoa fora de possibilidade de cura precisa permanecer próximo da família recebendo cuidados e conforto ${ }^{20}$.

Alguns profissionais de saúde, diante o diagnóstico de paciente fora da possibilidade de cura, se afastam destes devido acreditar que não há mais nada o que fazer, a não ser a espera da morte. Contudo, sabe-se que quando há controle dos sintomas físicos e do sofrimento do paciente, este pode encontrar outros significados para sua vida, mesmo quando surgem preocupações durante a doença. Durante a evolução da doença, entre os pacientes podem ocorrer momentos de rever a vida, resolver conflitos e de se preocupar com a família após sua morte ${ }^{8}$.

Em paciente fora de possibilidade de cura, o reconhecimento da finitude humana e dos cuidados paliativos são primordiais para favorecer condições favoráveis à promoção da qualidade de vida (QV) e do bem-estar dessas pessoas, sendo que a ausência ou negligência de algum desses itens pode comprometer a pessoa que se encontra fragilizada. É preciso capacitar os profissionais de saúde quanto a esses pacientes no sentido de sensibilizá-los, uma vez que pessoas acometidas por doença incurável demandam cuidados humanizados, com o propósito de respeitar sua dignidade e aliviar o sofrimento nesse momento de sua vida. Neste contexto, é necessário a implementação dos cuidados paliativos fundamentado nos princípios bioéticos que contemplem a ética da vida ${ }^{19}$.

Há poucas unidades de cuidados paliativos no Brasil e, em sua maioria, são mais comuns na atenção domiciliar de classes mais favorecidas financeiramente. O cuidado paliativo valoriza a relação interpessoal entre as pessoas que prestam cuidados e as que recebem, sendo as intervenções técnicas secundárias ${ }^{21}$.

Entre as características inerentes aos cuidados paliativos encontra-se a relevância da interação e do respeito de todos os envolvidos, visando o bem-estar do paciente que se sobrepõe a interesses diversos. Para tanto, há necessidade de ofertar educação permanente aos profissionais que trabalham com essa modalidade de cuidados e propiciar discussões sobre a prática dos cuidados paliativos com enfoque nos princípios bioéticos ${ }^{19}$.

É primordial inserir os cuidados paliativos a uma proposta de cuidados mais humanizados, valorizando assim, o respeito e a solidariedade das pessoas. A humanização dos cuidados para paciente fora de possibilidade de cura torna-se ainda mais necessário devido a situação que o mesmo se encontra, logo, essa demanda precisa ser discutida e praticada pelos profissionais de saúde $^{20}$.

A política nacional de humanização traz alguns princípios que podem nortear as práticas dos profissionais de saúde, dentre eles, a valorização da dimensão subjetiva e social das pessoas nas práticas de atenção e de gestão no SUS, com o intuito de fortalecer o compromisso com os direitos do cidadão; ofertar trabalho em equipe multiprofissional, com o propósito de concretizar a transversalidade e a grupalidade nas ações e; favorecer a autonomia e o protagonismo dos indivíduos e coletividade envolvidos na rede do SUS ${ }^{7}$.

Dentre as diversas doenças que podem acometer as pessoas de diversas faixas etárias se encontra o câncer. Este, por sua vez, pode evoluir e ter prognóstico ruim, levando o paciente a quadro de terminalidade da vida e necessitar de cuidados paliativos.

É visto que apesar dos avanços tecnológicos e divulgação na mídia de resultados positivos com relação ao câncer, a confirmação do diagnóstico e o planejamento do tratamento para o paciente exigem sensibilidade da equipe de saúde devido a complexidade de alguns casos. Após diagnóstico, é necessário que a equipe 
utilize linguagem simples durante as orientações do paciente e de sua família, para que os mesmos conheçam sobre a doença e o tratamento, isso favorece a confiança na equipe ${ }^{22}$.

Os enfermeiros que cuidam de pacientes oncológicos se deparam com desafios em sua prática como o de encontrar significados e respostas aos questionamentos do processo de viver, seja eles relacionados ao adoecer, curar ou morrer, assim como de implementações para alívio do sofrimento. Para esses pacientes, a humanização do cuidado parece ser bastante evidenciada no cuidado, o que pode ser influenciar na doença, no sofrimento, na terapêutica e no tempo em que o paciente fica sob os cuidados da equipe de saúde ${ }^{9}$.

Estudo realizado com enfermeiros que cuidavam de crianças oncológicas em cuidados paliativos descreve que o profissional de saúde necessita desenvolver cuidado centrado na criança que vivência a situação de viver\morrer, contudo, a família precisa ser inserida. A comunicação com os pais e/ou responsáveis da criança é essencial para promover a saúde e o cuidado, assim como os profissionais carecem proporcionar assistência integral, com valorização dos aspectos biológico, psicológico, social, econômico, espiritual e cultural ${ }^{23}$.

Para os enfermeiros, cuidar de pacientes com câncer, apesar de, muitas vezes, causar sofrimento, pode ocasionar sentimentos de gratificação. Para esses profissionais, entre os cuidados que podem ser ofertados, um toque ou um gesto de carinho pode contribuir para 0 paciente valorizar, dentro de suas possibilidades, pequenas atitudes que podem leva-lo a sorrir, a seguir em frente, e sobretudo, propiciar bemestar e melhor qualidade ao tempo de vida que ele tiver ${ }^{9}$.

É reconhecida a importância e a valorização dos cuidados paliativos para os pacientes na terminalidade da vida, assim como de estratégias como a da comunicação. Para os enfermeiros, a comunicação fortalece 0 vínculo entre 0 profissional, o paciente fora de possibilidade de cura e a família, assim como é elemento eficaz para a promoção do cuidado paliativo ${ }^{24}$.

Para o enfermeiro é completo ofertar apoio à família do paciente fora de possibilidade terapêutica. Esses profissionais encontram-se dificuldades em assistir a família, sobretudo, devido à situação de dor e sofrimento que se encontra. Essa demanda de cuidado torna-se ainda mais complexo quando o enfermeiro é recém-formado, pois há carência durante a formação acadêmica de temáticas direcionadas aos pacientes fora de possibilidade de cura e de sua família ${ }^{25}$.

Os profissionais de saúde, entre eles o enfermeiro, para assistir a família de pacientes fora de possibilidades de cura de forma efetiva precisam adquirir conhecimentos sobre o processo morte/morrer, aprender a lidar com seus medos, adquirir habilidades e ter atitudes aliadas a seus valores pessoais, ter postura profissional adequada à situação específica da família $^{25}$. Para tanto, estudo mostra que diante os princípios das diretrizes curriculares nacionais, é preciso a reflexão sobre a inserção do ensino formal de oncologia enquanto disciplina nos currículos de graduação em enfermagem ${ }^{26}$.

Estudo demonstrou que os enfermeiros lidam com situações de morte/morrer recorrente em sua atuação, logo, reconhecem a necessidade de preparo destes para lidar com os pacientes fora de possibilidade de cura. Entre os enfermeiros, alguns tiveram durante a graduação contato com situações de terminalidade, outros somente no ambiente de trabalho. Nota-se que a capacitação favorece o desenvolvimento de assistência efetiva para o paciente e menos estresse para o profissional ${ }^{11}$.

Os profissionais de saúde, dentre eles o enfermeiro, estão em contato direto e constante com o sofrimento ao atuar nos cuidados às crianças em cuidados paliativos e sua família. Os profissionais, na maioria das vezes, são formados objetivando a cura do paciente e a morte não é vista como possibilidade de cuidado, mas como fracasso e impotência dos profissionais ${ }^{23}$.

O cuidado do enfermeiro frente ao paciente fora de possibilidade de cura não pode ser interrompido diante das diversas situações em que o paciente se encontra. Para seu fortalecimento, é importante que o processo de morte/morrer seja mais explorado durante a formação profissional ${ }^{11}$.

\section{Conclusões}

Evidenciou-se que embora têm ampliado o avanço tecnológico em relação ao diagnóstico e tratamento do câncer, várias são as pessoas que se encontram acometidas por esta doença, sem possibilidade de cura e em cuidados paliativos.

Entre os enfermeiros, vários têm desenvolvido prática baseada no modelo biomédico, não se sentem preparados e apresentam dificuldades para cuidar de forma humanizada de pacientes oncológicos fora de 
possibilidade de cura, assim como têm dificuldades de lidar com o processo de morte e morrer. Isso tem relação com vários fatores, entre eles o déficit de oportunidades durante a graduação com esses pacientes e de educação permanente. Para tanto, há necessidade de capacitação específica desses profissionais para cuidar desses pacientes.

A comunicação efetiva entre enfermeiros e outros profissionais de saúde, assim como pacientes e familiares nos cuidados paliativos é considerada estratégias essencial na humanização do cuidado à pacientes oncológicos fora de possibilidade de cura. Contudo, há déficit de comunicação na equipe multiprofissional, o que, de certa forma, compromete a qualidade do cuidado paliativo.

$\mathrm{O}$ cuidado paliativo precisa ser direcionado à pessoa, conforme sua singularidade, com valorização da família durante o cuidado. Neste contexto, os enfermeiros têm apontado a relevância do diálogo, carinho, respeito a autonomia e alívio da dor dos pacientes fora de possibilidade de cura, com o propósito de minimizar o sofrimento.

\section{Referências}

1. Gutierrez PL. O que é o paciente terminal? Àbeira do leito. Rev Ass Med. 2001,47(2): 85-109.

2. Organização Mundial de Saúde apud Matsumoto, DY. Cuidados Paliativos: conceitos, fundamentos e princípios. In: Manual de Cuidados Paliativos ANCP, Academia Nacional de Cuidados Paliativos - ANCP. 2a ed. 2012. Disponível www.paliativo.org.br/dl.php?bid=146

3. Instituto Nacional de Câncer. Diagnóstico e tratamento-estadiamento. Rio de Janeiro, 1999. Disponível em: http://www.inca.com.br

4. Instituto Nacional de Câncer. Estimativa da incidência e mortalidade por câncer no Brasil. Rio de Janeiro, 2013. p.1.Disponível em: http://www.inca.gov.br/wcm/dmdc/2016/numer os-cancer-brasil.asp

5. Paiva FCL, Junior JJA, Damásio AC. Ética em cuidados paliativos: concepções sobre o fim da vida. Rev bioét. 2014, 22 (3): 550-60.

6. Silva EP, Sudigursky D. Concepção sobre cuidados paliativos: revisão bibliográfica. Acta Paul Enferm. 2008, 21(3): 504-8.

7. Brasil. Ministério da Saúde (MS).
Documento Base para Gestores e Trabalhadores do Sus: HumanizaSus. Brasília: MS, 2010. Disponível em: http://bvsms.saude.gov.br/bvs/publicacoes/hum anizasus documento gestores trabalhadores su s.pdf

8. Mendes JA, Lustosa MA, Andrade MCM. Paciente terminal, Família e Equipe de Saúde. Rev SBPH. 2009, 12(1): 151-73.

9. Gargiulo CA, Melo MCSC, Salimena AMO, Bara VMF, Souza IEO. Vivenciando o cotidiano do cuidado na percepção de enfermeiras oncologicas. Texto contexto-enferm. 2007, 16(4): 696-702.

10. Hermes HR, Lamarca ICA. Cuidados paliativos: uma abordagem a partir das categorias profissionais de saúde. Ciênc saúde coletiva. 2013,18(9):2577-88.

11. Furtado OAM, Souza SSRO, Ramos SJ, Ferreira M CA. O enfermeiro frente ao paciente forra de possibilidade terapêutica: dignidade e qualidade no processo do morrer. Enfermería Global. 2011, 10(22):1-8.

12. Silva MM, Santanda NGM, Santos MC, Cirilo JD, Barrocas DLR, Moreira MC. Cuidados paliativos na assistência de alta complexidade em oncologia: percepção de enfermeiros. Esc Anna Nery. 2015, 19(3):460-6.

13. Peterson AA, Carvalho EC. Comunicação Terapêutica na Enfermagem: dificuldades para o cuidar de idosos com câncer. Rev Bras Enferm. 2011, 64(4): 692-7.

14. Monteiro ACM, Rodrigues BMRD, Pacheco STA. O enfermeiro e o cuidar da criança com câncer sem possibilidade de cura atual. Esc Anna Nery. 2012, 16 (4):741-6.

15. França JRFS, Costa SFG, Lopes MEL, Nóbrega MML, França ISX. Importância da comunicação nos cuidados paliativos em oncologia: enfoque na Teoria Humanística de Enfermagem. Rev Latino-Am. Enferm. 2013, 21(3):07.

16. Souza LF, Misko MD, Silva L, Poles k, Santos MR, Bousso RS. Morte digna da criança: percepção de enfermeiros de uma unidade de oncologia. Rev Esc Enferm USP. 2013, 47(1):30-7.

17. Silva MM, Moreira MC. Sistematização da assistência de enfermagem em cuidados paliativos na oncologia: visão dos enfermeiros. Acta Paul Enferm, 2011, 24(2):172-8.

18. Silveira NR, Nascimento ERP, Rosa LM, Jung W, Martins SR, Fontes MS. Cuidado paliativo e enfermeiros de terapia intensiva: sentimentos que ficam. Rev Bras Enferm. 2016, 69(6):1074-81. 
19. Sousa ATO, França JRFS, Santos MFO, Costa SFG, Souto CMRM. Cuidados paliativos com pacientes terminais: um enfoque na bioética. Rev Cubana de Enfermagem. 2010, 26(3)117-129.

20. Santana JCB, Campos ACV, Barbosa BDGC, Baldessari CEF, Paula KF, Rezende MAE et al. Cuidados paliativos aos pacientes terminais: percepção da equipe de enfermagem. Bioethikos - Centro Universitário São Camilo. 2009, 3(1):7786.

21. Simoni $M$, Santos ML. Considerações sobre o cuidado paliativo e trabalho hospitalar: uma abordagem plural sobre o processo de trabalho de enfermagem. Psicologia USP. 2003,14(2):169-194.

22. Paro D, Paro J, Daise LMF. O enfermeiro e o cuidar em oncologia pediátrica. Arq Ciênc Saúde. 2005, 12(3):151-7.

23. Avanci BS, Carolindo FM, Góes FGB, Netto NPC. Cuidados paliativos à criança oncológica na situação viver\morrer: A ótica do cuidar em enfermagem. Rev Enferm Esc Anna Nery. 2009, 13 (4): 708-16.

24. Andrade CG, Costa SFG, Lopes MEL. Cuidados paliativos: a comunicação como estratégias de cuidado para o paciente em fase terminal. Ciênc saúde coletiva. 2013, 18 (9): 2523-30.

25. Fernandes MFP, Komessu JH. Desafios do enfermeiro diante da dor e do sofrimento da família de pacientes fora de possibilidade terapêuticas. Rev Esc Enfem USP. 2013, 47(1):250-7.

26. Calil AM, Prado C. Ensino de oncologia na formação do enfermeiro. Rev Bras Enferm. 2010, 63(4): 671-4.

\section{Endereço para Correspondência}

Universidade Federal da Bahia - UFBA

Rua Augusto Viana, s/n - Palácio da Reitoria, Canela, Salvador

CEP.: 40110-909

e-mail: karla.ferraz@hotmail.com

Recebido em 08/06/2017

Aprovado em 09/11/2017

Publicado em 05/12/2017 